\title{
Spatial distribution of US employment in an urban efficiency wage setting
}

\author{
José Ignacio Giménez-Nadal, ngimenez@unizar.es \\ University of Zaragoza (Spain), BIFI (Spain) and CTUR (UK) \\ José Alberto Molina, jamolina@unizar.es \\ University of Zaragoza (Spain), BIFI (Spain) and IZA (Germany) \\ Jorge Velilla, jvelilla@unizar.es \\ University of Zaragoza (Spain)
}

Mailing address of authors: Department of Economic Analysis, Faculty of EconomicA and Business, C/ Gran Vía 2, $3^{\text {rd }}$ floor. 50005 Zaragoza, Spain.

Correspondence to José Ignacio Giménez-Nadal.

\begin{abstract}
We analyze whether efficiency wages operate in urban labor markets, within the framework proposed by Ross and Zenou (2008), in which shirking at work and leisure are assumed to be substitutes. We use unique data from the American Time Use Survey (ATUS) that allow us to analyze the relationships between leisure, shirking, commuting, employment, and earnings. We confirm that shirking and leisure are substitutes, and present an estimate of this relationship, representing the only empirical test of the
\end{abstract}


relationship between a worker's time endowment and shirking at work. Our findings point to the existence of efficiency wages in labor markets.

Keywords: urban efficiency wages, leisure, shirking at work, commuting JEL Codes: J21, J22, J31, R12, R41.

\section{ACKNOWLEDGEMENTS}

This paper was partially written while José Alberto Molina was Visiting Fellow at Boston College's Department of Economics, to which he would like to express their thanks for the hospitality and facilities provided. This paper has benefited from funding from the Spanish Ministry of Economics (ProjectECO2012-34828). We want to thank Yves Zenou, the Editor, and the referees for the many helpful comments and suggestions, which we think have been very helpful in improving the quality of the paper. 


\section{INTRODUCTION}

In this paper, we analyze the spatial distribution of US employment, using data for the United States for the period 2003-2014. Employment and wages have been studied in a variety of frameworks, with one approach being the theory of efficiency wages, in which firms are willing to pay workers more than expected to promote efficiency and discourage shirking at work (Shapiro and Stiglitz, 1984). However, these authors identify the problem of setting efficiency wages when workers' time endowment is unobserved, since the value of shirking depends upon the time endowments. Following this approach, Ross and Zenou (2008) use expected commuting time as a shock to the time endowments to indirectly test the Shapiro and Stiglitz (1984) phenomena, which is the only test of this phenomena to date. Specifically, Ross and Zenou (2008) develop a model to examine the effects of commuting on employment and wages, in which the behavioral substitution between leisure time and effort at work is allowed. According to this model, employees who devote comparatively more time to commuting have comparatively less time to devote to leisure activities, and thus have incentives to shirk at work, which decreases their effort at work. However, a key theoretical ambiguity emerges from this model, as it is not known whether shirking at work and leisure are complements or substitutes and the authors derive all their results from the assumption that leisure and shirking at work are, indeed, substitutes

Our primary goal is to directly analyze the empirical relationship between shirking at work and leisure, and thus identify a key parameter that is necessary to test the efficiency wage hypothesis, using employment, wages, and leisure. To that end, we use the American Time Use Survey (ATUS) for the years 2003-2014, which allows us to observe the hours of work, and also to determine whether (and to what extent) non-work activitiesare performed during work hours. Such non-work activity during work hours is 
a key dimension of shirking, that is emphasized by Ross and Zenou (2008) as being especially sensitive to commuting time. We analyze how much time workers spend in non-work activities during their work schedules, and whether shirking at work (i.e., non-work activities done in the work place, such as internet shopping, managing household finances, or internet use on social networks) and leisure are complements or substitutes. We find evidence of substitutability between leisure and shirking at work, a critical assumption made in the current framework.

Following the theoretical framework, the negative relationship between leisure and shirking at work implies that commuting time has a negative relationship with leisure, while commuting has a positive relationship with shirking at work. We find that commuting time and leisure have a negative relationship for both supervised and nonsupervised occupations. We also find that the positive relationship between commuting time and shirking time is only found in non-supervised occupations, which may indicate that the payment of efficiency wages, in concert with supervision, reduces the incentives to shirk in supervised occupations. Thus, our results are consistent with the theoretical model. Furthermore, we analyze the relationship between commuting time, unemployment, and wages, and find that commuting time presents positive and statistically significant correlations with unemployment and wages.

Our contribution to the literature is twofold. First, we analyze the relationship between shirking at work and leisure, which is our main contribution. The Ross and Zenou (2008) model identifies a key theoretical ambiguity in this relationship, and no empirical analyzes have been done, so far, to determine the direction and magnitude of this relationship. We offer a precise estimation of the magnitude of this relationship, providing empirical support to Ross and Zenou (2008). Second, we complement prior results for employment and wages. Our results show positive relationships between 
commuting time, on the one hand, and unemployment and wages, on the other, which is consistent with urban efficiency wage theories. Thus, we offer updated evidence of the spatial distribution of US wage employment and individual earnings.

The rest of the paper is organized as follows. Section 2 briefly describes the theoretical background. Section 3 describes the data, and Section 4 contains an analysis of the relationships between shirking at work and leisure time. In Section 5, we show the results regarding commuting, shirking at work, leisure, employment, and wages, and Section 6 presents our main conclusions.

\section{THEORETICAL BACKGROUND}

The relationship between employment, earnings, and commuting has been widely studied. Examples of analyses of employment and commuting can be found in White (1977), Zax and Kain (1991), Clark and Withers (1999) and Rouwendal and Meijer (2001), where the importance of housing/residential decisions is highlighted. ${ }^{1}$ The Spatial Mismatch Theory (Kain, 1968) argues that poor labor market outcomes are partly the result of spatial separation between work and places of residence, and its effects on unemployment have been studied in Brueckner and Zenou (2003) (the contributions in this field are reviewed in Gobillon, Selod and Zenou, 2007). Patacchini and Zenou (2007) show the growing spatial dependence of unemployment rates, and Picard and Zenou (2015) find that minority groups have higher unemployment rates, independently of where they are located.

The effect of commuting on wages has also been studied, finding positive and robust associations. For instance, Leigh (1986) was one of the first to study compensating wages due to commuting, finding positive evidence, especially for white workers. Other 
authors analyzing the effects of commuting on wages are Zax (1991), White (1999), Rupert, Stancanelli, and Wasmer (2009), Fu and Ross (2013) and Mulalic, van Ommeren, and Pilegaard (2014). Brueckner, Thisse, and Zenou (1997)study the location of individuals in cities by income, finding that the availability of amenities in the various areas of the city is related to the location of the wealthy.

Among the different frameworks established to analyze these economic outcomes, the theory of urban efficiency wages is a common approach. According to efficiency wage models, salaried workers receive higher wages than expected from the labor market equilibrium, as firms are willing to pay workers more to promote efficiency and discourage shirking at work. However, firms do not pay enough to eliminate all shirking at work if they do not observe individual time endowments (Shapiro and Stiglitz, 1984). The urban efficiency wage models include a spatial pattern, where place of work and place of residence play an important role in determining how employment and unemployment are spatially distributed. One important factor in this framework is the distance from the place of residence to the workplace, which determines the time devoted to commuting. Thus, a key factor in urban wage efficiency models is commuting, which affects employment and wages.

We take the model of Ross and Zenou (2008) as our reference theoretical framework, where workers' residential locations remain fixed as they enter and leave unemployment. These authors establish an instant utility function of workers that depends on a non-spatial composite $\operatorname{good}(Z)$ consumed by the employed, and a function $(\mathrm{V}()$.$) that depends on leisure and effort at work, and considers that effort and leisure$ are not independent activities. ${ }^{2}$ In this sense, the authors' key assumption is that shirking at work and leisure are substitutes, as follows: low leisure at home may imply that the worker has less time for rest and relaxation and is more pressed for time at home, and 
thus the benefit of taking leisure (or conducting home production) while at work increases. ${ }^{3}$ No empirical analyses have been done, to date, to test this assumption (i.e., leisure and shirking at work are substitutes), where we would expect a negative relationship between leisure and shirking at work. Following this assumption, the model establishes that longer commuting time implies less time available for leisure (a negative relationship between commuting and leisure time), which increases the benefits of shirking at work (a positive relationship between commuting and shirking time).

In Ross and Zenou (2008), two scenarios are considered. ${ }^{4}$ The first refers to a situation where firms do not observe worker's location, and the authors establish three propositions. Proposition 1considers that workers who reside close to their jobs will choose not to shirk (i.e. will provide more effort), whereas workers located farther away will shirk (i.e. will provide less effort). Proposition 2 establishes that higher wages reduce the fraction of shirkers in the city, in the sense that, when wages are higher, fewer workers will shirk since there are more incentives not to do so. In equilibrium, the authors find that employment is lower when commuting times are longer (i.e., unemployment and commuting times should have a positive relationship). This labor market equilibrium is compatible with the existence of a certain degree of shirking at work, as firms will always want to allow some degree of shirking at work (Proposition 3).

The second scenario of the model considers that firms observe workers' locations. In this scenario, firms can know the commuting time of workers, and thus it is optimal for firms to wage-discriminate in terms of location and not allow shirking at work in equilibrium. Wages are higher when commuting times are longer, given that if leisure and effort are substitutes, wages must compensate workers who live farther away, since 
they commute more and thus have less time for leisure at home (Proposition 4). As a result, wages increase with distance to jobs; that is, we would expect a positive relationship between commuting time and wages.

In summary, three aspects of the model are to be tested: 1) a negative relationship between shirking and leisure time (i.e., shirking and leisure are substitutes, a key assumption of the model), 2) a negative association between commuting and leisure time, and positive associations between commuting time, shirking time, and wages (longer commuting times imply less leisure time, which induces shirking at work, encouraging firms to pay higher wages), and 3)a positive association between unemployment rates and (expected) commuting time, as shirking incentives increase in the (expected) commuting time.

\section{DATA AND VARIABLES}

We use the American Time Use Survey (ATUS) for the period 2003-2014 to analyze the relationship between shirking at work and leisure, along with the links between commuting time, on the one hand, and shirking time, leisure time, employment, and wages, on the other. Respondents fill out a diary, and the ATUS thus provides us with information on individual time use, including information that can be used to compute the time devoted to shirking at work, leisure, and commuting time. The database also includes certain personal, family, demographic, and labor variables. The ATUS is administered by the Bureau of Labor Statistics, and is considered the official time use survey of the United States (more information can be found at http://www.bls.gov/tus/). The advantage of our data over surveys based on stylized questions is that diary-based estimates are more accurate (Juster and Stafford, 1985; Robinson, 1985; Bianchi et al., 2000; Bonke, 2005; Yee-Kan, 2008). 
Our sample consists of employed and unemployed respondents between 16 and 65 years of age.For employed individuals, we restrict the analysis to working days, defined as days individuals spend more than 60 minutes working (excluding commuting), which allows us to avoid computing zero minutes of commuting for any worker who filled out the time use diary on a non-working day. ${ }^{5}$ One of the relationships to be tested is between commuting and unemployment, and in this analysis we include in our sample both the employed and the unemployed. For the analysis of the relationship between shirking and leisure time, and between commuting, shirking, leisure, and wages, we restrict the sample to workers only. ${ }^{6}$ The final sample consists of 33,360 employed individuals, and 5,651 unemployed individuals.

According to Ross and Zenou (2008), workers can be divided into white collar workers and blue collar workers; that is, slightly supervised workers and heavily supervised workers, respectively. Ross and Zenou (2008) base their classification on Levenson and Zoghi (2006), whose authors identify a clear break in the pattern of supervision, with all major white collar occupations having a predicted supervision level between 0.62 and 0.66 , and all major blue collar occupations having a predicted level of supervision between 0.34 and 0.45 , on a scale between zero and one where one implies independence from supervision. The ATUS includes information on occupations, with a ten-category classification: 1) Production, 2) Construction and extraction, 3) Installation and maintenance, 4) Transportation and materials, 5) Farming, fishing, and forestry, 6) Office and administrative, 7) Services, 8) Professional and related, 9) Sales, and 10) Management and business. Within this framework, we consider slightly supervised occupations (i.e., non-supervised) to be the following: "Management, business and financial", "Professional and related", "Service", and "Sales and related". This leaves us with "Office and administrative support", "Farming, 
fishing, and forestry", "Construction and extraction", "Installation, maintenance, and repair", "Production" and "Transportation and material moving" as heavily supervised occupations (i.e., supervised). ${ }^{7}$

The fact that we have information on the 24 hours of the day allows us to compute the total time devoted to shirking at work and to leisure, and discern the relationship between these two uses of time. We compute the time devoted to leisure by workers in our sample using the definition of Gimenez-Nadal and Sevilla (2012) and Aguiar and Hurst (2007): activities such as watching television, sports, general out-of-home leisure, gardening and pet care, and socializing, not at work. For the time devoted to shirking at work (i.e., non-work activities), the data structure of the ATUS allows us to ascertain the time workers report not working while in the work place. We define shirking time as the total time spent at the workplace, but which is not defined as market work. For instance, time spent on leisure, personal care, or housework (e.g., online shopping) done at the workplace (location code, "place of work") is included in the definition of shirking time. ${ }^{8}$ This definition of shirking time is related to the "loafing" time described in Burda, Genadek and Hamermesh (2015), defined as the time spent by workers in non-work activities while on the job.

\section{(PLACE TABLE 1 HERE)}

Table 1 shows a descriptive analysis of leisure and shirking time, for all workers and by group of supervision. We observe that average leisure and shirking times are 88.78 and 27.54 minutes per day, with standard deviations of 87.78 and 34.78 , respectively. Thus, workers in the US spend around 30 minutes per working day in shirking activities. By group of workers, we find that workers in occupations with supervision spend 86.21 and 35.66 minutes in leisure and shirking activities, while workers in occupations without supervision spend 90.21 and 23.05 minutes in these 
activities, respectively. Thus, in comparison to workers in occupations without supervision, those in occupations with supervision spend 4 fewer minutes per day in leisure activities and 12.61 more minutes per day in shirking activities, with this difference being statistically significant at the 99 percent level ( $p$-values of the differences in characteristics based on a $t$-type test). Table 2 shows the means and standard deviations of the time devoted to shirking by workers, according to their occupation. By occupation, we find that workers in production occupations spend the most time (42.25 daily minutes) in shirking at work, while workers in management and business, and sales occupations spend the least time (17.83 and 20.45 daily minutes, respectively) in shirking at work.

\section{(PLACE TABLE 2 HERE)}

The ATUS also includes information on labor earnings, which allows us to compute the hourly wage of workers. We have defined "hourly earnings" directly as earnings per hour, if this data was available from ATUS; in other cases, we have defined it as earnings per week divided by the usual weekly working hours. Data collected in ATUS are in nominal terms, and thus we have transformed nominal hourly wages to real hourly wages by dividing nominal wages by the price deflator from the Federal Reserve, Bank of St. Louis. For workers in our sample, Table 1 shows that the average hourly earnings are $\$ 19.59$, and the standard deviation is $\$ 17.60$.

We define other variables in order to control for the observed heterogeneity of individuals in the econometric analysis done in Sections 4 and 5. We consider the gender of respondents (male), potential years in the labor market (age minus number of education years and minus a fixed value, taken as 3), education level, being white, and being American, Asian, or Pacific Islander, living in couple, partner's labor force status (a dummy variable that indicates whether or not the partner works), having children, 
and the number of individuals in the household. We consider three levels of education: "basic education" (less than high school diploma), "secondary education" (high school diploma), and "university education" (more than high school diploma), defining each as a dummy variable. We have also included "years in labor market squared" (Ross and Zenou, 2008), in order to measure non-linear effects.

Table 1 shows a descriptive analysis of the variables, by group. In comparison with the unemployed, the employed have a higher probability of being women (52.7 percent vs 45.4 percent), have greater experience in the labor market (20.45 vs 19.27 years); a higher proportion of them have University education (63.3 percent vs 46.7 percent), and they are more likely to be white ( 82.4 percent vs 71.4 percent), although there is a higher proportion of Asian employees than unemployed (4.1 percent vs 2.7 percent). Regarding the variables related to household composition, we observe that, in comparison with the unemployed, employed workers have a greater probability of living in couple (60.4 percent vs 46.1 percent) and that their partners have a greater probability of being employed (45 percent vs 33.3 percent), have fewer children (53.6 percent of the employees have children, vs 56.9 percent of the unemployed), and thus their households are smaller (2.9 members of the employees vs 3.1 of the unemployed). When we compare workers in occupations with and without supervision, we find that the former earn $\$ 5.90 /$ hour less than the latter $(\$ 15.77 /$ hour vs. $\$ 21.70 /$ hour). Furthermore, workers in occupations with supervision show lower rates of University education, have longer experience in the labor market, and have a lower probability of having children, in comparison with workers in occupations without supervision.

\subsection{Descriptive evidence}

From the evidence presented in Tables 1 and 2, we can determine that the higher the shirking time the lower the leisure time, which points to leisure and shirking at work 
being substitutes. To test this relationship, we have directly analyzed the raw correlation between leisure and shirking time. Figure 1 plots the average time devoted to leisure, for each time devoted to shirking at work; that is, for all those diaries with the same amount of time devoted to shirking at work, we average the time devoted to leisure. We plot mean leisure time (y-axis) on the time devoted to shirking at work (x-axis). We have also added a linear fit of leisure time on shirking time. The linear fit shows a negative slope between leisure and shirking time, with the correlation between them being -0.242 . We find positive evidence of the substitutability of leisure and shirking at work, which complements Ross and Zenou (2008) as, a priori, they do not know whether shirking at work and leisure are complements or substitutes.

\section{(PLACE FIGURE 1 HERE)}

If shirking at work and leisure are substitutes, it follows that commuting and shirking at work are positively related, while commuting and leisure are negatively related. Thus, we now analyze the relationships between commuting time, on the one hand, and leisure and shirking time, on the other. Commuting time is the time devoted to the activity "commuting to/from work", coded as "180501" in the ATUS. Table 1 shows the time devoted to commuting by workers in our sample. It can be seen that workers devote an average of 38.68 minutes per day to commuting, with workers in supervised and non-supervised occupations devoting 39.55 and 38.20 minutes per day, respectively. From Table 1,we find that workers in supervised occupations devote more time to commuting, which results in less time in leisure and more time in shirking at work, in comparison with workers in occupations without supervision. To test these relationships, we directly analyze the raw correlation between commuting, leisure, and shirking time. Figure 1 plots the average time devoted to commuting, for each time devoted to leisure, on the one hand, and for each time devoted to shirking at work, on 
the other. We plot mean leisure time, and mean shirking time (x-axis), on the time devoted to commuting (y-axis). We have also added a linear fit of leisure and shirking times on commuting time. We observe a negative slope between commuting and leisure times - the correlation between them is -0.169 - on the one hand, and a positive slope between commuting and leisure times - the correlation between them is $0.154-$ on the other. We conclude that there is a negative association between commuting and leisure, and a positive association between commuting and shirking at work, consistent with Ross and Zenou (2008).

Figure 2 shows the evolution of employment and unemployment rates, hourly wages, and commuting time in the US, from the ATUS. We observe that the employment rate has decreased, while the unemployment rate, hourly wages, and commuting time have increased over the period. The increase in commuting time in recent years is consistent with the findings of Kirby and LeSage (2009), McKenzie and Rapino (2011), and Gimenez-Nadal and Molina (2014, 2016).Apart from economic conditions, which influence employment and unemployment rates, among the explanations for these trends we can find the increase in commuting time, leading to increases in unemployment rates and hourly wages.

\section{(PLACE FIGURE 2 HERE)}

In summary, we find that the relationship between leisure and shirking at work is negative. Accordingly, the relationship between commuting and leisure is negative, and commuting has positive relationships with shirking time, unemployment, and wages,giving empirical support to the model ofRoss and Zenou (2008). However, in this analysis we do not control for other factors that may be affecting these relationships, and the evidence presents a first descriptive analysis. In the following Sections, we analyze these relationships, controlling for other factors. 


\section{THE RELATIONSHIP BETWEEN SHIRKINGAT WORK AND LEISURE}

According to the theoretical framework, the key assumption in the model is that leisure and shirking at work are substitutes, and thus we should find a negative relationship between them. Hence, we analyze the relationship between leisure and shirking time, once we control for other observed factors that may condition this relationship. To that end, we limit the sample to employed individuals only, and estimate Ordinary Least Squared (OLS) models of shirking time, as follows:

$$
\text { Shirking }_{\text {is }}=\alpha_{0}++\alpha_{1} \mathrm{~L}_{\text {is }}+\alpha_{2} \mathrm{X}_{\text {is }}+\alpha_{3} \mathrm{~W}_{\text {is }}+\alpha_{\mathrm{s}}+\varepsilon_{\text {is }}
$$

where Shirking is represents the $(\log )$ of shirking time of a given individual " $i$ " living in Metropolitan Statistical Area(MSA)“s", and $\mathrm{L}_{\text {is }}$ represents the( $\left.\log \right)$ of leisure time of that individual. This specification of the model resembles that of Ross and Zenou (2008). $\mathrm{X}_{\text {is }}$ includes the set of socio-demographic characteristics described in Section 3, $\mathrm{W}_{\mathrm{is}}$ represents housing attributes, $\alpha_{\mathrm{s}}$ represents MSA fixed effects, and $\varepsilon_{\mathrm{is}}$ represents random variables capturing unmeasured factors and measurement errors. ${ }^{9}$ Given that the ability to shirk across occupations and industries may vary, we also include occupation and industry fixed effects in our estimates. Regarding the information on the attributes of the household unit $\left(\mathrm{W}_{\mathrm{is}}\right)$, we consider the information on whether the housing unit is owned or not, with the following options: Owned or being bought by a household member; Rented for cash, and Occupied without payment of cash rent (reference category).Given the theoretical framework, we should expect that $\alpha_{1}<0$.

Columns (1) and (2) of Table 3 show the results of estimating Equation (1) for both supervised and non-supervised workers, respectively. We find that the time workers devote to leisure is negatively related to the time they devote to shirking at work, with 
this correlation being statistically significant at the 90 percent level in the case of the supervised workers, and at the 99 percent level in the case of the non-supervised workers. Specifically, we find that a decrease of 10 percent in leisure time is related to increases of 0.32 percent and 1.11 percent in the time that employees devote to shirking activities at work. Then, the less time devoted to leisure activities, the more time workers devote to shirking at work, which points to the validity of the main assumption of Ross and Zenou (2008).

\section{(PLACE TABLE 3 HERE)}

Furthermore, the negative relationship between shirking and leisure time is stronger for workers in non-supervised occupations, given its larger coefficient and higher level of significance. This difference may indicate that workers in non-supervised occupations find it easier to shirk at work, in comparison with supervised workers; once they are paid efficiency wages, workers in non-supervised occupations do not risk being fired when they shirk, while workers in supervised occupations may find it more difficult to shirk, due to monitoring.

\section{COMMUTING, SHIRKING AT WORK, EMPLOYMENT AND WAGES}

\subsection{Commuting time, leisure and shirking}

We first analyze the relationship between commuting, and leisure and shirking time, which supposes the first empirical test on these relationships to the authors' knowledge. From the theoretical framework, if leisure and shirking at work are substitutes, we would expect to find a negative relationship between commuting and leisure time, and a positive relationship between commuting and shirking time. We limit the sample to employed individuals only, and estimate OLS models: 


$$
\mathrm{T}_{\text {is }}=\alpha_{0}++\alpha_{1} \mathrm{C}_{\mathrm{is}}+\alpha_{2} \mathrm{X}_{\mathrm{is}}+\alpha_{3} \mathrm{~W}_{\mathrm{is}}+\alpha_{\mathrm{s}}+\varepsilon_{\text {is }}
$$

where $T_{\text {is }}$ represents the (log) leisure or shirking time of a given individual " $i$ " living in MSA "s", and $C_{i s}$ represents the (log) commuting time of that individual. The vectors $\mathrm{X}_{\mathrm{is}}, \mathrm{W}_{\text {is }}$ and $\alpha_{\mathrm{s}}$ are the same as in Equation (1). We also include occupation and industry fixed effects in our estimates.

Columns (1) and (3) in Table 4 show the results of estimating Equation (2) on leisure and shirking time for workers in supervised occupations, and Columns (2) and (4) in Table 4 show the results of estimating Equation (2) on leisure and shirking time for workers in non-supervised occupations. We find that commuting time has a negative relationship with leisure for workers in both supervised and non-supervised occupations, with this relationship being statistically significant at the 99 percent level. An increase of 10 percent in the time devoted to commuting by workers is related to decreases in leisure time of 0.96 percent and 1.35 percent for workers in supervised and non-supervised occupations, respectively. A t-type test of the equality of coefficients does not allow us to reject the null hypothesis of the equality of coefficients, and thus we cannot conclude that the magnitude of the relationship differs by the level of supervision. The negative relationship between commuting and leisure time contained in the model is confirmed by our results.

\section{(PLACE TABLE 4 HERE)}

One important ambiguity in the Ross and Zenou (2008) model is that they do not know the magnitude of the negative relationship between commuting and leisure. Time use data allows for the minimization of measurement error in both commuting and leisure time, and thus we can estimate the magnitude of this relationship by analyzing partial correlations. Results indicate that this relationship is less than 1, since the 
elasticity is lower than unity, and the confidence intervals at the 95 percent confidence level all include values lower than one (e.g., $-0.114,-0.775$ and $-0.147,-0.122$ for workers in supervised and non-supervised occupations, respectively). This evidence indicates that, as commuting time increases, workers adjust their hours of work to limit the reduction in their leisure.

Focusing on the relationship between commuting and shirking time, we find mixed results, depending on the type of occupation. The conditional correlation between commuting and shirking time is positive and statistically significant at the 99 percent significance level for workers in non-supervised occupations, while it is not statistically significant in those occupations that can be considered as not supervised. For workers in non-supervised occupations, an increase of 10 percent in the time devoted to commuting is associated with an increase of 2.07 percent in the shirking time of workers. However, the correlation between commuting and shirking time for workers in supervised occupations indicates that an increase of 10 percent in the time devoted to commuting is associated with an increase of only 0.3 percent in shirking time. We find evidence that is consistent with Ross and Zenou (2008) regarding the relationship between commuting and shirking time, and our results indicate that workers in non-supervised occupations find it easier to shirk at work, in comparison with supervised workers.

\subsection{Commuting time, employment and wages}

We next focus on the relationship between commuting time and the hourly wages of employed workers. According to Ross and Zenou (2008), we should expect to find a positive relationship between commuting time and wages. These relationships are set in equilibrium under different scenarios (i.e., no observation, or observation of worker's 
location, respectively), and hence the estimation of conditional correlations between commuting and earnings is sufficient to test the existence of efficiency wages. We estimate OLS models of the logarithm of hourly wages on commuting time. ${ }^{10}$ The statistical model is as follows:

$$
\mathrm{WE}_{\mathrm{is}}=\alpha_{0}++\alpha_{1} \mathrm{C}_{\mathrm{is}}+\alpha_{2} \mathrm{X}_{\mathrm{is}}+\alpha_{3} \mathrm{~W}_{\mathrm{is}}+\alpha_{\mathrm{s}}+\varepsilon_{\text {is }}
$$

where $\mathrm{WE}_{\mathrm{is}}$ represents the (log) hourly wage of a given individual "i" living in MSA "s", and $\mathrm{C}_{\mathrm{is}}$ represents the( $\left.\log \right)$ time devoted to commuting by that individual. The vectors $\mathrm{X}_{\mathrm{is}}, \mathrm{W}_{\mathrm{is}}$ and $\alpha_{\mathrm{s}}$ are the same as in Equations (1) and (2). We also include occupation and industry fixed effects in our estimates.Given the theoretical framework, the relationship between commuting and wages is expected to be positive, $\alpha_{1}>0$, consistent withthe existing literature (van Ommeren, van den Berg and Gorter, 2000; Ross and Zenou, 2008; Rouwendal and Nijkamp, 2004; Dargay and van Ommeren, 2005; Susilo and Maat, 2007; Rupert, Stancanelli, and Wasmer, 2009; Gimenez-Nadal, Molina, and Velilla, 2015).

Columns (1) and (2) of Table 5 show the results of estimating Equation (3) for the sample of workers in supervised and non-supervised occupations, respectively(see Table A3 in the Appendix for results of other socio-demographic variables). We find that commuting time is positively related to hourly wages for both supervised and nonsupervised occupations, with this relationship being statistically significant at the 95 percent level. In particular, we find that an increase of 10 percent in commuting time is related to an increase in wages of 0.19 percent and 0.16 percent for workers in supervised and non-supervised occupations, respectively. A $t$-type test of the equality of coefficients does not allow us to reject the null hypothesis of the equality of coefficients, and thus we cannot assume that the magnitude of the relationship differs by 
the level of supervision of the occupations. This evidence is consistent with the existence of efficiency wages in the US, as firms can discriminate wages in an attempt to avoid shirking, although shirking is not fully eliminated, as workers still devote time to shirking activities.

\section{(PLACE TABLE 5 HERE)}

Our results differ from those presented in Ross and Zenou (2008) because they find that efficiency wages only operate for occupations with high levels of supervision (e.g., blue collar workers). However, Ross and Zenou (2008) argue that results for lightlysupervised occupations (e.g., white collar workers) are not robust, as their estimates may suffer from a weak instrument problem that biases the IV estimates towards OLS estimates. Within this framework, we choose to estimate OLS models for wages, given that the dataset allows for a more accurate measure of commuting time in comparison with prior research, and the use of predicted commuting would make this benefit marginal. Given that these relationships are obtained in the market equilibrium, we do not attempt to estimate causal effects, but rather we are interested in equilibrium relationships, and the estimation of conditional correlations using OLS models is sufficient to test for the relationships predicted by the model. Furthermore, a firm can choose between more supervision and higher wages to compensate for the commutinginduced incentives to shirk. Accordingly, commuting should induce higher wages in occupations where firms cannot supervise. In contrast, in occupations where supervision is possible, firms can partly offset the necessary wage increases by increased offshoring. Thus, theoretically, there is no reason to think that commuting may have a stronger effect on wages in supervised occupations compared to occupations where supervision is not feasible. 
Finally, we analyze the relationship between the employment and commuting time of individuals, where a negative relationship is expected. One important issue is that commuting time is not observed for the unemployed, which leads to selection bias. Thus, we must predict the commuting times of unemployed individuals and, to that end, we follow Ross and Zenou (2008) and apply an approach based on the identification of the effect of location (i.e., commuting) on outcomes, using cross-metropolitan variations (Cutler and Glaeser, 1997). ${ }^{11}$ Ross and Zenou (2008) identify the effect of commuting time by the exclusion from the labor market equation of certain factors that can explain commuting time differences. With this approach, the source of variation for identification comes from cross-metropolitan area differences in commuting times (see Ross and Zenou, 2008, for a discussion of this approach).

But we cannot estimate specific models of commuting time for each MSA individually, as there are several MSAs with less than 30 observations and we must be cautious in making estimates for specific metropolitan areas. Alternatively, we interact the housing stock variables with region variables included in the ATUS, exploiting systematic differences between the structure of metro areas in different regions of the country. In particular, we interact the information regarding ownership (i.e., owned, rented, other) with the information on census region of residence (i.e., Northeast, Midwest, South, West), and thus the model is identified by the exclusion from the labor market equation of the interaction of region Fixed Effects with the housing stock variables. We estimate an OLS model on commuting time, and we then predict commuting times for both the employed and the unemployed. ${ }^{12}$

For the relationship between commuting and employment, we estimate an OLS model as follows: ${ }^{13}$

$$
\mathrm{E}_{\mathrm{is}}=\beta_{0}+\beta_{1} \widehat{\mathrm{C}_{1 \mathrm{~s}}}+\beta_{2} \mathrm{X}_{\mathrm{is}}+\beta_{3} \mathrm{~W}_{\mathrm{is}}+\alpha_{\mathrm{s}}+\varepsilon_{\mathrm{ils}}
$$


where, for a given individual "i" living in MSA "s", $\mathrm{E}_{\mathrm{is}}$ is the dummy variable "employed" that takes value " 1 " if he/she is an employed worker, and value " 0 " if he/she is unemployed. $\widehat{\mathrm{C}_{1 \mathrm{~s}}}$ represents the log of commuting time of individual " $\mathrm{i}$ " living in MSA "s", predicted using the commuting model described in the previous paragraph. The vectors $X_{i s}, W_{\text {is }}$ and $\alpha_{s}$ are the same as in Equations (1), (2) and (3).Given our theoretical framework, we expect commuting time to have a negative relationship to employment, $\beta_{1}<0$. We bootstrap the standard errors of the regressions, given that we are using generated variables in the model (Pagan, 1984; Murphy and Topel, 2002; Gimenez-Nadal and Molina, 2016), and we produce 500 replications of the model, where a random sample with replacement is drawn from the total number of observations.

Column (3) of Table 5 shows the results of the key explanatory variables when we estimate Equation (4) for the employment regression without including commuting time, while Column (4) shows the results for employment when we include predicted commuting time. We find that commuting time presents a negative and statistically significant correlation with the probability of being employed. ${ }^{14}$ Specifically, we find that an increase in commuting time of 10 percent is associated with a decrease in the probability of employment of 0.6 percent. These results are consistent with Ross and Zenou (2008), and can be interpreted as that employed workers are located closer to work places, compared to the unemployed from their potential work places.

Regarding the consistency of our results, when we compare the coefficients from Columns (3) and (4), we observe that the introduction of an imputed variable does not significantly bias the estimated coefficients, as coefficients for the other explanatory variables do not vary much, and their statistical significance remains. However, the limitation of the data regarding housing attributes may mean that these variables do not 
contain sufficient variation to identify the coefficients of commuting, leading to a problem analogous to the weak instrument problem. ${ }^{15}$ Ross and Zenou (2008) acknowledge that they suffer from a weak instruments problem, and thus commuting time estimates trend toward zero, as estimates with weak instruments are biased towards the OLS estimates (Bound et al., 1995; Zivot, Startz and Nelson, 1998). Thus, we have reasons to believe that our results are also biased toward zero, and we are offering a lower bound of the relationship.

\section{CONCLUSIONS}

Analyses of employment and earnings and their spatial distribution are common, and a rich literature on the interactions with commuting time has emerged, where efficiency wage theory represents an important strand in this field of research. In this paper, we use a framework based on the model of Ross and Zenou (2008)on efficiency wages, where behavioral substitution between leisure time and effort at work is allowed. The relationship between leisure and shirking at work has not been previously analyzed, and we shed light on this relationship. We find positive evidence of the substitutability between leisure and shirking at work, and thus we offer a precise estimation of the magnitude of this relationship and provide empirical support to the Ross and Zenou (2008) assumption. Furthermore, our results confirm all the relationships derived from the model. We find that commuting time has a negative relationship with leisure, while it has a positive relationship with shirking time. Additionally, we find that commuting time presents positive relationships with unemployment and wages, which can be interpreted as evidence of efficiency wages, as firms can discriminate wages in terms of location in an attempt to deter shirking. 
Furthermore, the shirking time of non-supervised occupations is affected by commuting time, perhaps because they do not risk being fired if they shirk. If workers are not supervised, with longer commuting times they have less leisure time and should thus be more likely to shirk (as shirking and leisure are substitutes). Being nonsupervised, they do not risk their jobs, so they are not deterred from shirking. On the contrary, the shirking time of supervised occupations is not affected by commuting time, which is consistent with the fact that, if workers are paid efficiency wages, then firms would pay higher wages when commuting distance increases, to discourage shirking. Due to the higher wages, workers' incentives to shirk decline, so there is no net effect on shirking time

Other authors have analyzed commuting and wages, such as in the Ross and $\mathrm{Fu}$ (2013) model of agglomeration economies. These authors find that wage premia arise from location differences (both agglomeration and productivity), finding a positive association between workplace agglomeration and wages, robust to residential location fixed effects. Their model implies that commuting should correlate with wages, in order to ensure that similar individuals have the same utility across different work locations, even though wages differ across these locations. The efficiency wage model has a different implication, because real wages vary based on individual commutes. The results presented in this paper regarding commuting, shirking, and leisure provide empirical support to the Ross and Zenou (2008) model on efficiency wages. Further analysis of the existence of efficiency wages in other countries is proposed as a promising line of research.

Despite that we do not deal with causality, which may represent a limitation in the current context, the theoretical framework allows us to analyze conditional correlations, in order to test the model and determine whether efficiency wages operate in labor 
markets. However, in our analysis, we only consider the supply side of the job market, in the sense that only worker decisions are analyzed, and the demand side of job positions is not considered. This limitation is important in the current context, as for instance, the availability of jobs is important in determining whether individuals remain unemployed or prefer to be employed. Further analysis should extend our results by incorporating the supply side of the market.

Finally, one limitation of the paper is that we have considered the amount of time devoted to non-work activities in the work place as a measure of shirking behavior. However, we must acknowledge that this is an incomplete measure of effort at work. Becker (1985) assumes that firms buy a package of time and effort (i.e., intensity of work) from each worker, and payments to workers are according to these two components. Thus, the first component refers to the amount of time devoted to work, while the second component refers to the intensity of workers while doing their work tasks. According to this definition of effort at work (amount of time and intensity of worked hours), shirking behavior could well affect the hours of work, the intensity of worked hours, or both. In the current context, we are only considering shirking behavior referred to hours of work, but the intensity of work is not taken into account, which may help to explain our result that, for workers in supervised occupations, shirking time is not affected by commuting time. Monitoring practices in supervised occupations imply thatsuch workers risk their jobs if they shirk, and they may find it more beneficial to modify the intensity of their work tasks. Further analysis should extend our results by incorporating this aspect. 


\section{FOOTNOTES}

1. Renkow and Hoover (2000) empirically study urban change following the regional restructuring hypothesis and the deconcentration hypothesis, supporting the latter in opposition to the former. The regional restructuring hypothesis holds that employment opportunities have been dominant over spatial employment changes, while the deconcentration hypothesis proposes that such changes are due to consumer preferences.

2. Two studies are relevant in this context. Van Ommeren and Gutiérrez-i-Puigarnau (2011) analyze the effect of the length of the worker's commute on productivity, by examining whether the commute has a positive effect on absenteeism, considering absenteeism as the opposite to productivity. The authors find that absenteeism in Germany would be 15 percent to 20 percent less if all workers had a negligible commute, which is consistent with urban efficiency wage models. Burda, Genadek and Hamermesh (2015) study shirking ("not working at job", or loafing) and unemployment, in a setting robust to the operation of efficiency wages, where wage compensations discourage workers from loafing.

3. It is also theoretically possible that leisure and shirking are complementary concepts. Changes in commuting time (and thus in leisure) may distort social life and thus the more time devoted to commuting, the less quality of social life and benefits from leisure, implying fewer planned activities at home. This decline makes the demand for personal time activities decline, including the benefits derived from personal activities at work. Since there is less time for planned activities at home, there is more time available for relaxing, so relaxing time at work also declines. However, Ross and Zenou (2008) argue that the case where effort and leisure are complements is not consistent with the results shown in their paper (footnote 7). 
4. An intermediate scenario considers that firms partially observe workers' locations. In this scenario, commuting time is only partially observed, in the sense that firms may observe residential location, but it is too costly for firms to determine the true commutes of workers. Firms will pay efficiency wages to reduce shirking, but they will not know the exact premium needed to compensate the workers. Within this framework, some workers will shirk, and the relationships between commuting, unemployment, and wages will hold with the existence of shirking.

5. We have repeated the analysis without restricting by working days, but controlling for weekdays, and results are qualitatively the same. Results are available upon request. For the restriction to working days, we define the variable "market work time" as the time devoted to the sum of "work, main job (not at home)", "working nec (not at home)", "work-related activities nec (not at home)", "work \& related activities nec (not at home)" and "waiting work related activities (not home)".

6. Since there is no point in talking about efficiency wages in self-employment, as they do not receive wages, we restrict our sample of workers to those who are employees. A complete modeling and analysis of the relationship between commuting and selfemployment can be found in Gimenez-Nadal, Molina and Velilla (2017).

7. We must highlight that the ATUS is not intended as a labor survey. Thus, information on occupation is only available for those who are employed, while there is no information on previous occupation for those who are not employed (i.e., inactive, unemployed, retired). That way, the type of supervision of individuals is only known for employed individuals, while it is not known for the unemployed. For this reason, in our analysis of unemployment, we cannot divide the analysis by the level of supervision, and we run the analysis for the employed vs. the unemployed. For the rest of the 
analysis (commuting, shirking, leisure, and wages), given that we focus on workers only, we divide the sample into supervised and non-supervised occupations.

8. In a previous version of the paper, we also included the time devoted to work breaks and meals at work in the definition of shirking time. However, breaks and time for meals may be a standard part of work and it may be considered odd to mark these activities as shirking behavior. Results are consistent to the inclusion of these activities in our definition of shirking, and are available upon request.

9. The information about the MSA of residence follows the US Census Bureau's categorization of metropolitan areas. Despite that the Census Bureau's terminology for metropolitan areas, and the classification of specific areas, changes over time, the general concept is consistent: a metropolitan area consists of a large population center and adjacent communities that have a high degree of economic and social interaction. The geographic information included in the ATUS includes the metropolitan area of residence of individuals.

10. An alternative approach is to estimate the causal effect of the commute on wages, where worker characteristics that affect commuting time, but not wages, are needed to identify the effect. Despite that we cannot talk about causality, Ross and Zenou (2008) establish that the analysis of conditional correlations is also valid in the current context. Prior research analyzing the causal effect of commuting on wages includes Mulalic, van Ommeren and Pilegaard (2014) and Freund et al. (2015). We estimate the transformation to logarithm because the distribution of the variable does not follow a normal distribution (see Figure A1 in the Appendix) and thus we try to normalize the variable by applying a log transformation. 
11. This approach has been applied in a variety of studies, including Evans, Oates and Schwab (1992), Cutler and Glaeser (1997), Hoxby (2007), Card and Rothstein (2007), and Ross and Zenou (2008).

12. Sum stats of the housing and census region variables, and the results of the commuting model, can be found in Tables A1 and A2 of the Appendix, respectively.

13. We have alternatively estimated a Logit model on the probability of employment, and results are robust to the use of different econometric models. We thus rely on the OLS model, given that coefficients can be interpreted directly, and results for the Logit model are available upon request.

14. Our results may, in principle, be affected by sample selection issues, as the selection of employed and unemployed individuals may lead to the existence of subgroups with low labor-market attachment. Thus, we have estimated our employment model with an alternative subsample, to minimize the share of individuals with a low labor market attachment. We have considered unemployed individuals who report looking for a job during the four weeks prior to the survey. Also, we have predicted the time devoted to commuting separately by gender, and by the level of education. Results are robust and are shown in Table A5 of the Appendix.

15. We have tested the extent to which the instrument can be explained by observed predetermined attributes (e.g., gender, education), which would imply a source of bias. We have regressed predicted commuting time on the set of socio-demographic $\left(\mathrm{X}_{\mathrm{is}}\right)$ variables used to predict commuting time (e.g., region fixed effects and type of ownership), and we then run an F-test for whether the demographics can explain expected commuting. We obtain that the F-test is significant. Thus, predicted commuting can be explained by observed predetermined attributes and so is likely to be correlated with unobserved attributes, which implies a source of bias. This is also the 
case in Ross and Zenou (2008), who argue that cross-metropolitan differences in the spatial distribution of owner-occupied housing is not clearly exogenous, and we acknowledge that our results for employment may be biased.

\section{REFERENCES}

Aguiar, Mark, \& Hurst, Erik (2007). Measuring trends in leisure: the allocation of time over five decades. Quarterly of Journal Economics, 122(3), 969-1007.

Bianchi, Suzanne M., Milkie, Melissa A., Sayer, Liana C., \& Robinson, John P. (2000). Is anyone doing the housework? Trends in the gender division of household labor. Social Forces, 79(1), 191-228.

Becker, Gary S. (1985). Human Capital, Effort, and the Sexual Division of Labor. Journal of Labor Economics, 3(1, Part 2), S33-S58.

Bonke, Jens (2005). Paid work and unpaid work: Diary information versus questionnaire information. Social Indicators Research. 70(3), 349-368.

Bound, John, Jaeger, David A., \& Baker, Regina M. (1995). Problems with instrumental variables estimation when the correlation between the instruments and the endogenous explanatory variable is weak. Journal of the American statistical association, 90(430), 443-450.

Brueckner, Jan K., Thisse, Jacques F., \& Zenou, Yves (1997). Why is central Paris rich and downtown Detroit poor? An amenity-based theory. European Economic Review, 43(1), 91-107.

Brueckner, Jan K., \& Zenou, Yves (2003). Space and Unemployment: The LaborMarket Effects of Spatial Mismatch. Journal of Labor Economics, 21(1), 242- 
266.

Burda, Michael C., Genadek, Katie R., \& Hamermesh, Daniel S. (2015). Not working at work: Loafing, Unemployment and Labor Productivity (IZA Discussion Paper No. 9095).

Card, David, \& Rothstein, Jesse (2007). Racial segregation and the black-white test score gap. Journal of Public Economics, 91(11), 2158-2184.

Clark, William A., \& Withers, Suzanne D. (1999). Changing jobs and changing houses: mobility outcomes of employment transitions. Journal of Regional Science, 39(4), 653-673.

Cutler, David M., \& Glaeser, Edward L. (1997). Are ghettos good or bad? Quarterly of Journal Economics, 112, 827-872.

Dargay, Joyce M., \& Van Ommeren, Jos N. (2005). The effect of income on commuting time using panel data.Paper presented at the45th Conference of the European Regional Science Association at the Vrije Universiteit Amsterdam, Amsterdam.

Evans, William N., Oates, Wallace E., \& Schwab, Robert M. (1992). Measuring peer group effects: A study of teenage behavior. Journal of Political Economy, 100(5), 966-991.

Freund, Florian, Hawranek, Franziska, vom Berge, Philipp, \& Heuermann, Daniel F. (2015). The Distributional Effect of Commuting Subsidies-Evidence from GeoReferenced Data and Large-Scale Policy Reform. Paper presented at theAnnual Conference 2015 (Muenster): Economic Development-Theory and Policy, Session: Local Labor Markets 2 (No. F18-V2), Germany.

Fu, Shishe, \& Ross, Stephen L. (2013). Wage Premia in Employment Clusters: How Important is Worker Heterogeneity? Journal of Labor Economics, 31(2), 271-304. 
Gimenez-Nadal, JoseI., \& Molina, Jose A. (2014). Commuting Time and Labour Supply in the Netherlands: A Time Use Study. Journal of Transport Economics and Policy, 48(3), 409-426.

Gimenez-Nadal, Jose I., \& Molina, Jose A. (2016). Commuting Time and Household Responsibilities: Evidence using Propensity Score Matching. Journal of Regional Science, 56(2), 332-359.

Gimenez-Nadal, Jose I., Molina, Jose A., \& Velilla, Jorge (2015). Excess Commuting in the US: Differences between the Self-Employed and Employees (IZA Discussion Paper No. 9425).

Gimenez-Nadal, Jose I., Molina, Jose A., \& Velilla, Jorge (2017).Leisure and effort at work: incorporating self-employment into urban markets (MPRA Paper No.77972).

Gimenez-Nadal, Jose I., \& Sevilla, Almudena (2012). Trends in time allocation: a crosscountry analysis. European Economic Review, 56(6), 1338-59.

Gobillon, Laurent, Selod, Harris, \& Zenou, Yves (2007). The Mechanisms of Spatial Mismatch. Urban Studies, 44(12), 2401-2427.

Hoxby, Caroline M. (2007). Does competition among public school benefit students and taxpayers? American Economic Review, 97(5), 1209-1238.

Juster, Thomas, \& Stafford, Frank P. (1985). Time, Goods, and Well-Being. Ann Arbor, MI: Institute for Social Research, University of Michigan.

Kain, John F. (1968). Housing Segregation, Negro Employment, and Metro-politan Decentralization. Quarterly Journal of Economics, 82(2), 32-59.

Kirby, Dustin K., \& LeSage, James P. (2009). Changes in commuting to work times 
over the 1990 to 2000 period. Regional Science and Urban Economics, 39(4), $460-471$.

Leigh, J. Paul (1986). Are compensating wages paid for time spent commuting? Applied Economics, 18(1), 1203-1214.

Levenson, Alec R., \& Zoghi, Cindy (2006). The strength of occupational indicators as a proxy for skill. BLS Working Paper no. 404, U.S. Bureau of Labor Statistics.

McKenzie, Brian, \& Rapino, Melanie (2011). Commuting in the United Stated: 2009.Washington DC: U.S. Department of Commerce, Economics and Statistics Administration, U.S. Census Bureau.

Mulalic, Ismir, Van Ommeren, Jos N., \& Pilegaard, Ninette (2014). Wages and Commuting: Quasi-natural Experiments' Evidence from Firms that Relocate. Economic Journal, 124(579), 1086-1105.

Murphy, Kevin M., \& Topel, Robert H. (2002). Estimation and Inference in Two-Step Econometric Models. Journal of Business and Economic Statistics, 20(1), 88-97.

Van Ommeren, Jos N., van den Berg, Gerard J., \&Gorter, Cees (2000). Estimating the Marginal Willingness to Pay for Commuting. Journal of Regional Science, 40(3), $541-563$.

Van Ommeren, Jos N., \& Gutiérrez-i-Puigarnau, Eva (2011). Are workers with a long commute less productive? An empirical analysis of absenteeism. Regional Science and Urban Economics, 41(1), 1-8.

Pagan, Adrian (1984). Econometric Issues in the Analysis of Regressions with Generated Regressors. International Economic Review, 25(1), 221-247.

Patacchini, Eleonora, \& Zenou, Yves (2007). Spatial dependence in local 
unemployment rates. Journal of Economic Geography, 7(2), 169-191.

Picard, Pierre M., \& Zenou, Yves (2015). Urban Spatial Structure, Employment and Social Ties: European versus American Cities. IZA Discussion Paper No. 9166.

Renkow, Mitch, \& Hoover, Dale (2000). Commuting, Migration, and Rural-Urban Population Dynamics. Journal of Regional Science, 40(2), 261-287.

Robinson, John P. (1985). The validity and reliability of diaries versus alternative time use measures, in T. Juster \& F.P. Stafford (Eds.), Time, goods, and well-being (pp 33-62). Ann Arbor, MI: Institute for Social Research, University of Michigan.

Ross, Stephen L., \& Zenou, Yves (2008). Are Shirking and Leisure Substitutable? An Empirical Test of Efficiency Wages Based on Urban Economic Theory. Regional Science and Urban Economics, 38(5), 498-517.

Rouwendal, Jan, \& Meijer, Erik (2001). Preferences for housing, jobs, and commuting: a mixed logit analysis. Journal of Regional Science, 41(3), 475-505.

Rouwendal, Jan, \& Nijkamp, Peter (2004). Living in Two Worlds: A Review of Hometo-Work Decisions. Growth and Change, 35(3), 287-303.

Rupert, Peter, Stancanelli, Elena, \& Wasmer, Etienne. (2009). Commuting, Wages and Bargaining Power. Annals of Economics and Statistics, 95/96, 201-220.

Shapiro, Carl, \& Stiglitz, Joseph E. (1984). Equilibrium unemployment as a worker discipline device.American Economic Review, 74(3), 185-214.

Susilo, Yusak O., \& Maat, Kees (2007). The influence of built environment to the trends in commuting journeys in the Netherlands. Transportation, 34(5), 589-609.

United States Census Bureau (2015). Commuting (Journey to Work), online data

White, Michelle J. (1977). A model of residential location choice and commuting by 
men and women workers. Journal of Regional Science, 17(1), 41-52.

White, Michelle J. (1999). Urban areas with decentralized employment: Theory and empirical work. Handbook of Regional and Urban Economics, 3, 1375-1412.

Yee-Kan, Man (2008). Measuring Housework Participation: The Gap Between "Stylised" Questionnaire Estimates and Diary-Based Estimates. Social Indicators Research, 86(3), 381-400.

Zax, Jeffrey S. (1991). Compensation for commutes in labor and housing markets. Journal of Urban Economics, 30(2), 192-207.

Zax, Jeffrey S., \&Kain, John F. (1991). Commutes, quits and moves. Journal of Urban Economics, 29(2), 153-165.

Zivot, Erik, Startz, Richard, \& Nelson, Charles R. (1998). Valid confidence intervals and inference in the presence of weak instruments. International Economic Review, 39(4), 1119-1144. 
TABLE 1. Summary Statistics of Variables

\begin{tabular}{|c|c|c|c|c|c|c|c|c|c|c|c|c|}
\hline \multirow[b]{2}{*}{ VARIABLES } & \multicolumn{2}{|c|}{ Employed } & \multicolumn{2}{|c|}{ Unemployed } & \multicolumn{2}{|c|}{ Differences } & \multicolumn{2}{|c|}{ Supervised } & \multicolumn{2}{|c|}{ Non-supervised } & \multicolumn{2}{|c|}{ Differences } \\
\hline & Mean & S.D. & Mean & S.D. & Diff. & $p$-value & Mean & S.D. & Mean & S.D. & Diff. & $p$-value \\
\hline Leisure time & 88.782 & 87.778 & - & - & - & - & 86.208 & 85.526 & 90.208 & 88.972 & -4.000 & $(<0.001)$ \\
\hline Shirking time & 27.543 & 34.784 & - & - & - & - & 35.657 & 36.322 & 23.049 & 33.057 & 12.608 & $(<0.001)$ \\
\hline Commuting time & 38.682 & 40.782 & - & - & - & - & 39.554 & 40.923 & 38.198 & 40.696 & 1.356 & $(0.004)$ \\
\hline Hourly earnings & 19.588 & 17.597 & - & - & - & - & 15.772 & 9.625 & 21.702 & 20.429 & -5.931 & $(<0.001)$ \\
\hline Being male & 0.527 & 0.499 & 0.454 & 0.498 & 0.073 & $(<0.001)$ & 0.623 & 0.485 & 0.473 & 0.499 & 0.150 & $(<0.001)$ \\
\hline Years working & 20.454 & 11.546 & 19.275 & 12.704 & 1.179 & $(<0.001)$ & 21.844 & 11.621 & 19.685 & 11.432 & 2.159 & $(<0.001)$ \\
\hline Years working squared & 55.169 & 51.140 & 53.289 & 54.184 & 1.880 & $(<0.001)$ & 61.218 & 53.316 & 51.817 & 49.578 & 9.401 & $(<0.001)$ \\
\hline Primary education & 0.081 & 0.273 & 0.192 & 0.394 & -0.111 & $(<0.001)$ & 0.120 & 0.326 & 0.060 & 0.237 & 0.061 & $(<0.001)$ \\
\hline Secondary education & 0.286 & 0.452 & 0.340 & 0.474 & -0.055 & $(<0.001)$ & 0.426 & 0.495 & 0.208 & 0.406 & 0.218 & $(<0.001)$ \\
\hline University education & 0.633 & 0.482 & 0.467 & 0.499 & 0.166 & $(<0.001)$ & 0.453 & 0.498 & 0.733 & 0.443 & -0.279 & $(<0.001)$ \\
\hline Being white & 0.824 & 0.381 & 0.714 & 0.452 & 0.111 & $(<0.001)$ & 0.835 & 0.371 & 0.818 & 0.386 & 0.017 & $(<0.001)$ \\
\hline Being American & 0.824 & 0.381 & 0.820 & 0.385 & 0.005 & $(0.393)$ & 0.815 & 0.389 & 0.830 & 0.376 & -0.015 & $(<0.001)$ \\
\hline Being Asian & 0.041 & 0.197 & 0.027 & 0.161 & 0.014 & $(<0.001)$ & 0.022 & 0.148 & 0.051 & 0.219 & -0.028 & $(<0.001)$ \\
\hline Being Pacific Islander & 0.002 & 0.044 & 0.003 & 0.055 & -0.001 & $(0.120)$ & 0.002 & 0.047 & 0.002 & 0.043 & 0.000 & $(0.525)$ \\
\hline Living in couple & 0.604 & 0.489 & 0.461 & 0.499 & 0.143 & $(<0.001)$ & 0.609 & 0.488 & 0.601 & 0.490 & 0.008 & $(0.136)$ \\
\hline Partner's labor status & 0.450 & 0.498 & 0.333 & 0.471 & 0.117 & $(<0.001)$ & 0.438 & 0.496 & 0.457 & 0.498 & -0.019 & $(0.001)$ \\
\hline Have children & 0.536 & 0.499 & 0.569 & 0.495 & -0.033 & $(<0.001)$ & 0.526 & 0.499 & 0.541 & 0.498 & -0.015 & (0.009) \\
\hline Family size & 2.941 & 1.486 & 3.098 & 1.600 & -0.157 & $(<0.001)$ & 2.975 & 1.527 & 2.922 & 1.463 & 0.053 & $(0.002)$ \\
\hline N. Observations & \multicolumn{2}{|c|}{33,360} & \multicolumn{2}{|c|}{5,651} & & & \multicolumn{2}{|c|}{11,893} & \multicolumn{2}{|c|}{21,467} & & \\
\hline
\end{tabular}

Note: The sample (ATUS 2003-2014) is restricted to employees who work the diary-day (by supervision, if corresponding), or to unemployed individuals. Commuting, leisure and shirking times are measured in daily minutes. Working time is measured in weekly hours. Employed group collects salaried workers in private sector. Hourly earnings are measured in \$US. Gender takes the value 1 for men and 0 for women. "Years working squared" is defined as the square of years working, divided into 10, in order to normalize the scale. Occupation, Industry, and MSA statistical summaries are not shown in this table. Differences are defined as the mean value of the correspondent variable for private sector employees (supervised employees), minus the corresponding value for the unemployed (non-supervised employees). $T$-test $p$-values for the mean differences in parentheses. 
TABLE 2. Leisure and shirking times, by occupation

\begin{tabular}{llcccr}
\hline \multicolumn{1}{c}{ OCCUPATIONS } & \multicolumn{2}{c}{ Leisure time } & \multicolumn{2}{c}{ Shirking time } & N. Obs \\
\hline \multicolumn{1}{c}{ Management and business } & $\underline{\text { Mean }}$ & $\underline{\text { SD }}$ & $\underline{\text { Mean }}$ & $\underline{\text { SD }}$ & \\
Professional and related & 91.838 & 86.989 & 17.828 & 28.894 & 8,581 \\
Services & 92.475 & 87.111 & 21.441 & 31.264 & 11,117 \\
Sales & 89.119 & 94.595 & 25.919 & 37.277 & 6,848 \\
Office and administrative & 93.719 & 91.443 & 20.455 & 30.535 & 4,936 \\
Farming, fishing, and forestry & 85.481 & 83.106 & 30.735 & 34.494 & 5,498 \\
Construction and extraction & 90.306 & 88.244 & 32.387 & 37.638 & 346 \\
Installation and maintenance & 91.260 & 92.711 & 34.813 & 41.479 & 2,141 \\
Production & 89.344 & 84.108 & 33.099 & 33.993 & 1,637 \\
Transportation and materials & 87.896 & 86.176 & 42.254 & 36.742 & 2,768 \\
\hline
\end{tabular}

Note: The sample (ATUS 2003-2014) is restricted to private sector employees. Leisure and shirking times are measured in daily minutes. 
TABLE 3. Estimates of the shirking-leisure relationship

\begin{tabular}{|c|c|c|}
\hline \multirow[b]{3}{*}{ VARIABLES } & \multicolumn{2}{|c|}{ (1) (2) } \\
\hline & \multicolumn{2}{|c|}{ Log-shirking model } \\
\hline & Supervised & Non-supervised \\
\hline \multirow[t]{2}{*}{ Being male } & $0.157 * *$ & -0.010 \\
\hline & $(0.074)$ & $(0.049)$ \\
\hline \multirow[t]{2}{*}{ Years working } & 0.000 & $-0.018 * * *$ \\
\hline & $(0.006)$ & $(0.005)$ \\
\hline \multirow[t]{2}{*}{ Years working sq. } & 0.001 & $0.004 * * *$ \\
\hline & $(0.001)$ & $(0.001)$ \\
\hline \multirow[t]{2}{*}{ Secondary ed. } & -0.036 & -0.066 \\
\hline & $(0.051)$ & $(0.063)$ \\
\hline \multirow[t]{2}{*}{ University ed. } & $-0.262 * * *$ & $-0.366^{* * *}$ \\
\hline & $(0.056)$ & $(0.058)$ \\
\hline \multirow[t]{2}{*}{ Living in couple } & -0.047 & -0.041 \\
\hline & $(0.039)$ & $(0.037)$ \\
\hline \multirow[t]{2}{*}{ Family size } & 0.011 & $0.033 * *$ \\
\hline & $(0.018)$ & $(0.015)$ \\
\hline \multirow[t]{2}{*}{ Leisure } & $-0.032 *$ & $-0.114 * * *$ \\
\hline & $(0.018)$ & $(0.015)$ \\
\hline \multirow[t]{2}{*}{ Constant } & 0.155 & -9.837 \\
\hline & (12.020) & (18.836) \\
\hline Observations & 11,893 & 21,467 \\
\hline R-squared & 0.072 & 0.042 \\
\hline
\end{tabular}

Note: Robust standard errors in parentheses. The sample (ATUS 20032014 ) is restricted to private sector workers in supervised (Column 1) and non-supervised (Column 2) occupations. Dependent variables are the logarithms of daily minutes devoted to shirking. Leisure time is measured in log of minutes per day. All models control for housing attributes, MSA fixed effects, and industry and Occupation-MSA fixed effects. All standard errors are clustered at the Occupation-MSA level. Results for additional variables included in the regressions can be found in Table A3 of the Appendix.* Significant at the 90\% level. ** Significant at the 95\% level. *** Significant at the $99 \%$ level. 
TABLE 4. Estimates of the commuting-leisure and commuting-shirking relationships

\begin{tabular}{|c|c|c|c|c|}
\hline \multirow[b]{3}{*}{ VARIABLES } & \multirow{2}{*}{\multicolumn{2}{|c|}{$\begin{array}{l}\text { (1) } \\
\text { Log-leisure model }\end{array}$}} & \multirow{2}{*}{\multicolumn{2}{|c|}{$\begin{array}{l}\text { (3) } \\
\text { Log-shirking model }\end{array}$}} \\
\hline & & & & \\
\hline & Supervised & Non-supervised & Supervised & Non-supervised \\
\hline \multirow[t]{2}{*}{ Being male } & $0.091 * * *$ & $0.159 * * *$ & $0.154 * *$ & -0.053 \\
\hline & $(0.034)$ & $(0.023)$ & $(0.070)$ & $(0.048)$ \\
\hline \multirow[t]{2}{*}{ Years working } & $-0.014^{*}$ & $-0.027 * * *$ & 0.001 & $-0.015^{* * *}$ \\
\hline & $(0.008)$ & $(0.003)$ & $(0.006)$ & $(0.005)$ \\
\hline \multirow[t]{2}{*}{ Years working sq. } & $0.003^{*}$ & $0.006 * * *$ & 0.001 & $0.003 * *$ \\
\hline & $(0.002)$ & $(0.001)$ & $(0.001)$ & $(0.001)$ \\
\hline \multirow[t]{2}{*}{ Secondary ed. } & 0.056 & 0.031 & -0.038 & -0.074 \\
\hline & $(0.041)$ & $(0.074)$ & $(0.051)$ & $(0.065)$ \\
\hline \multirow[t]{2}{*}{ University ed. } & 0.064 & $0.153 * *$ & $-0.264 * * *$ & $-0.371 * * *$ \\
\hline & $(0.045)$ & $(0.065)$ & $(0.057)$ & $(0.062)$ \\
\hline \multirow[t]{2}{*}{ Living in couple } & $0.182 * * *$ & $0.179 * * *$ & -0.052 & $-0.074 * *$ \\
\hline & $(0.058)$ & $(0.041)$ & $(0.040)$ & $(0.036)$ \\
\hline \multirow[t]{2}{*}{ Family size } & $0.050 * * *$ & $0.041 * * *$ & 0.009 & 0.024 \\
\hline & $(0.013)$ & $(0.011)$ & $(0.018)$ & $(0.017)$ \\
\hline \multirow[t]{2}{*}{ Commuting } & $-0.096^{* * *}$ & $-0.135^{* * *}$ & 0.003 & $0.207 * * *$ \\
\hline & $(0.009)$ & $(0.006)$ & $(0.023)$ & $(0.036)$ \\
\hline \multirow[t]{2}{*}{ Constant } & -3.495 & 1.258 & 0.273 & -12.674 \\
\hline & $(6.091)$ & $(3.833)$ & (11.977) & (18.504) \\
\hline Observations & 11,893 & 21,467 & 11,893 & 21,467 \\
\hline R-squared & 0.032 & 0.042 & 0.072 & 0.058 \\
\hline
\end{tabular}

Note: Robust standard errors in parentheses. The sample (ATUS 2003-2014) is restricted to private sector workers in supervised occupations (Columns 1 and 3), and to private sector workers in non-supervised occupations (Columns 2 and 4). Dependent variables are the logarithms of the daily minutes devoted to leisure (Columns 1 and 2) and to shirking (Columns 3 and 4). Commuting time is measured in log of minutes per day. All models control for housing attributes, MSA fixed effects, and industry and Occupation-MSA fixed effects. All standard errors are clustered at the Occupation-MSA level. Results for additional variables included in the regressions can be found in Table A3 of the Appendix.* Significant at the $90 \%$ level. ** Significant at the $95 \%$ level. $* * *$ Significant at the $99 \%$ level. 
TABLE 5. Estimates of the commuting-employment and commuting-wages relationships

\begin{tabular}{|c|c|c|c|c|}
\hline \multirow[b]{3}{*}{ VARIABLES } & \multirow{2}{*}{\multicolumn{2}{|c|}{$\begin{array}{l}\text { (1) } \\
\text { Log-wage models }\end{array}$}} & \multirow{2}{*}{\multicolumn{2}{|c|}{$\begin{array}{l}3) \\
\text { Employment models }\end{array}$}} \\
\hline & & & & \\
\hline & Supervised & Non-supervised & General & $\begin{array}{l}\text { Predicted } \\
\text { commuting }\end{array}$ \\
\hline \multirow[t]{2}{*}{ Being male } & $0.218 * * *$ & $0.183 * * *$ & $0.027 * * *$ & $0.031 * * *$ \\
\hline & $(0.036)$ & $(0.017)$ & $(0.004)$ & $(0.003)$ \\
\hline \multirow[t]{2}{*}{ Years working } & $0.037 * * *$ & $0.037 * * *$ & $0.005 * * *$ & $0.005 * * *$ \\
\hline & $(0.003)$ & $(0.002)$ & $(0.001)$ & $(0.001)$ \\
\hline \multirow[t]{2}{*}{ Years working sq. } & $-0.007 * * *$ & $-0.007 * * *$ & $-0.001 * * *$ & $-0.001 * * *$ \\
\hline & $(0.001)$ & $(0.000)$ & $(0.000)$ & $(0.000)$ \\
\hline \multirow[t]{2}{*}{ Secondary ed. } & $0.212 * * *$ & $0.274 * * *$ & $0.095 * * *$ & $0.096 * * *$ \\
\hline & $(0.039)$ & $(0.040)$ & $(0.010)$ & $(0.008)$ \\
\hline \multirow[t]{2}{*}{ University ed. } & $0.330 * * *$ & $0.586^{* * *}$ & $0.138 * * *$ & $0.135 * * *$ \\
\hline & $(0.045)$ & $(0.056)$ & $(0.010)$ & $(0.007)$ \\
\hline \multirow[t]{2}{*}{ Living in couple } & $0.104 * * *$ & $0.171 * * *$ & $0.055 * * *$ & $0.058 * * *$ \\
\hline & $(0.025)$ & $(0.027)$ & $(0.007)$ & $(0.006)$ \\
\hline \multirow[t]{2}{*}{ Family size } & $-0.058 * * *$ & $-0.060 * * *$ & $-0.014 * * *$ & $-0.018 * * *$ \\
\hline & $(0.008)$ & $(0.009)$ & $(0.002)$ & $(0.002)$ \\
\hline \multirow[t]{2}{*}{ Commuting } & $0.019 * *$ & $0.016 * *$ & - & $-0.059 * *$ \\
\hline & $(0.009)$ & $(0.007)$ & - & $(0.029)$ \\
\hline \multirow[t]{2}{*}{ Constant } & $21.429 * * *$ & $72.535 * * *$ & $0.662 * * *$ & $0.858 * * *$ \\
\hline & $(3.921)$ & $(11.964)$ & $(0.028)$ & $(0.101)$ \\
\hline Observations & 11,893 & 21,467 & 38,305 & 38,305 \\
\hline R-squared & 0.132 & 0.215 & 0.068 & 0.06 \\
\hline
\end{tabular}

Note: Robust standard errors clustered at the Occupation-MSA levelin parentheses of Columns (1) and (2),bootstrapped $(n=500)$ standard errorsin parentheses of Columns (3) and (4). The sample (ATUS 2003-2014) is restricted to private sector workers in supervised (Column 1) and non-supervised (Column 2) occupations. The sample (ATUS 2003-2014) is restricted toprivate sector workers and to unemployed individuals (Columns 3 and 4). Dependent variables are the logarithm of hourly wages in \$US (Columns 1 and 2), and the dummy "Being employed" (Columns 3 and 4). Expected commuting times for Column (4) are measured in log of minutes per day. Gender takes the value 1 for men and 0 for women. All models control for housing attributes and MSA fixed effects, Columns (1) and (2) also control for industry and OccupationMSA fixed effects. Results for additional variables included in the regressions can be found in Table A4 of the Appendix. * Significant at the $90 \%$ level. ** Significant at the $95 \%$ level. *** Significant at the $99 \%$ level. 
FIGURE 1: Relationship between commuting, leisure, and shirking

Note: The sample (ATUS 2003-2014) is restricted to employed individuals. Commuting, leisure, and shirking are measured in minutes per day.
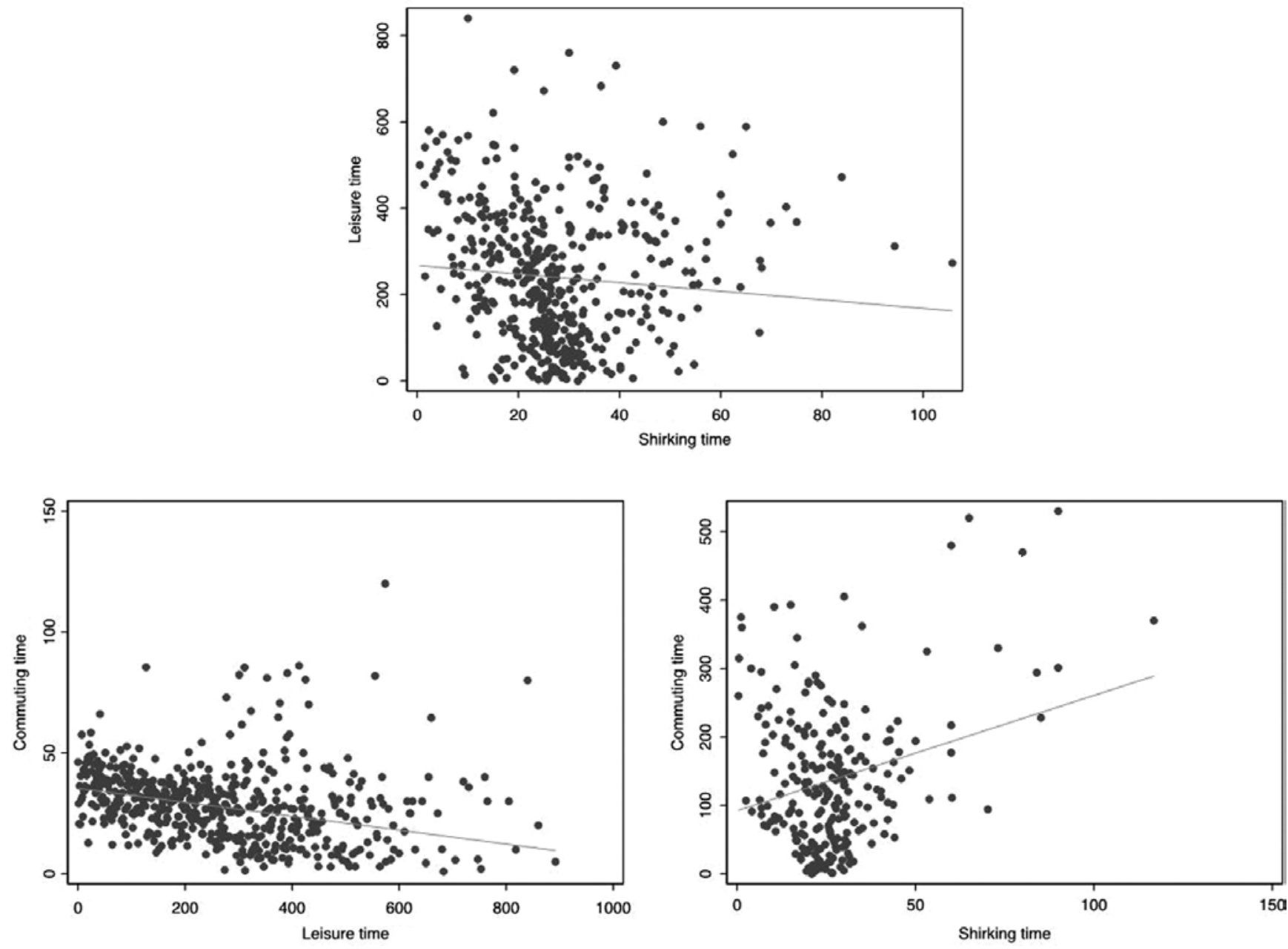
FIGURE 2: Evolution of employment, commuting, and hourly earnings

Note: The sample (ATUS 2003-2014) is restricted to employees. Average hourly earnings measured in Dollars per hour, deflated using the deflator of the Federal Reserve Bank of St. Louis. Commuting time is measured in minutes per day.
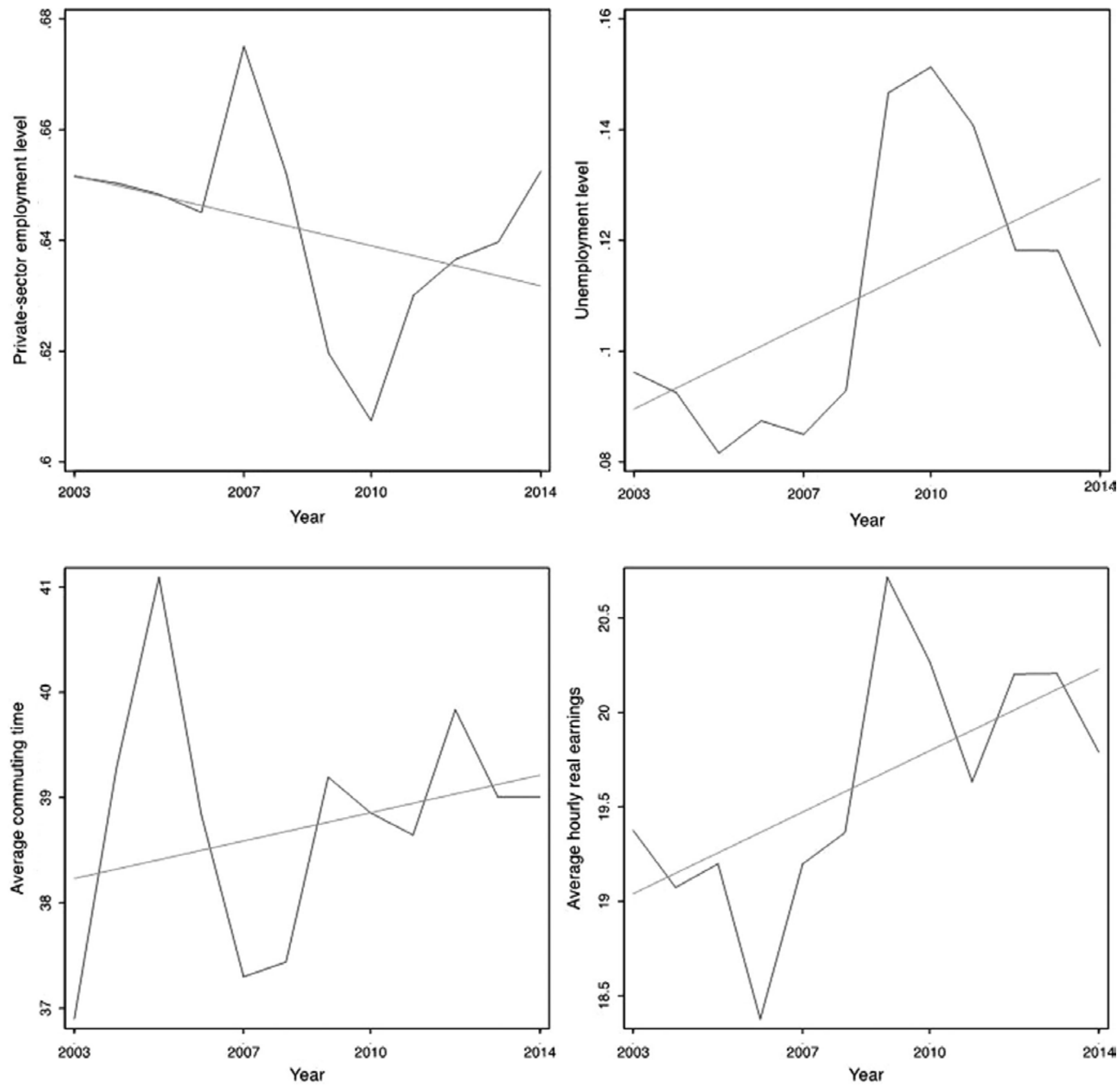